\title{
The Web of Time and the Dilemma of Globalization
}

\author{
Soraj Hongladarom \\ Department of Philosophy, Faculty of Arts, Chulalongkorn University, Bangkok, Thailand
}

Time is affected significantly by the spread of the Internet throughout the world. On the one hand, the new communication technologies provide for "round-the-clock" operation, threatening to obliterate time as a function of a culture's sense of identity. On the other hand, the Internet enables local cultures to resist the globalizing and homogenizing tide. The situation points to a dilemma. Local cultures find it hard to resist integrating itself with the world through the Internet, but at the same time they feel a real need to protect and to promote their identities. This article tries to show that local cultures find the medium an appropriate and effective one in putting forward their agenda. As the globalizing force signified by the Internet tends to occur at a superficial level, different conceptions of time can coexist at the same time. The emerging conception of time is thus characterized neither by the premodern one of identification of time with nature, nor by the modern one of an abstract entity pointing forward, but by a "web" allowing for different strands to go their own way while weaved together to create a coherent pattern, and this is how the dilemma is resolved. A case study of the Thai conceptions of time and the current debate on changing the time standard is presented in order to illustrate the point.

Keywords cultures, globalization, Internet, time

The spread of the Internet throughout the world is turning it into a powerful agent of globalization not only in economic but also in cultural and ideological terms. The compressed distance and time created by the Internet have brought about easier and faster communication, and the Internet itself has become a powerful ideological tool capable

Received 3 July 2000; accepted 21 September 2001.

This article is part of a research project on computer-mediated communication and Thai culture, funded by the Thailand Research Fund, under contract BRG/14/2544. I thank Prof. Vichai Boonsaeng for his support. I also thank the anonymous referees of The Information Society for their very helpful comments.

Address correspondence to Soraj Hongladarom, Department of Philosophy, Faculty of Arts, Chulalongkorn University, Bangkok 10330, Thailand. E-mail: hsoraj@chula.ac.th of altering how cultures and societies view themselves and their worlds. Local cultures face the problem of finding a balance between becoming totally immersed in the Internet, facing the possibility of losing their identities, and keeping the Internet out altogether, which would mean that the cultures in question would have to be isolated from the rest of the world.

In this article I look at one aspect of this important problem, namely, that of how the Internet is changing social and cultural conception s of time existing in a local culture. The spread of the Internet has raised an interesting question of how cybertime (as an analog to "cyberspace") and real time are connected. Since what exists on the Internet is often related to what is happening outside of it, a close look at how the Internet is changing temporal dimensions societies and cultures merits some serious attention. There have been a number of studies dealing with the effect of the Internet on temporality in organization s (e.g., Lee, 1999, and Lee \& Liebenau, 2000a). In this article, however, I explore how the Internet affects temporality on the social and cultural scale. I argue that the Internet and other information and communication technologies are likely to bring about a change in how time is conceived, a change that could be as significant as the changing conception of time that marked the dawn of the modern era. Just as there was a clear shift in conception of time and space when the European world, and later on other civilizations, emerged from the feudal and medieval era to become modern, so the shift engendered by the Internet and other information technologies could be just as momentous.

More specifically, I intend to show that the emerging conception is not characterized by the neat separation between the global and the local. Time, for example, does not exist as a linear, monolithic structure as it was during the era of railways and telegraphs. During this current age of MTV, live chat rooms, digitized currency trading, and globally organized protests against the WTO and the IMF, time exists in many different layers. The conflicting pulls between the felt need to integrate oneself with the world and the need to protect one's identity has created a dilemma. The emerging conception allows for a solution 
to the dilemma. Different conception s of time have to exist coherently together if the dilemma and its consequences are to be avoided. Following Jackson (1996), this new conception regards time as something that allows for many layers of the global-local time continuu m to exist together. Thus a way is found for local cultures to retain their identities while engaging themselves actively with the Internet and the world.

\section{MEDIEVAL CONCEPTION OF TIME}

The belief that authority emanates from a changeless and eternal metaphysical source, and that time itself, as part of nature, is part of the whole metaphysical system providing meaning to everything, characterizes the medieval, or premodern, world. Time does not exist as an abstract formulation of duration; instead, it is a tangible and integral part of life and reality. Without the mechanical means of measuring time, the medievals referred to memorable natural events as time markers and units of measurement of time smaller than the hour were rarely used (Burke, 1985, p. 93). Lee and Liebenau (2000b) also point out that before the invention of the reliable mechanical clock in 1657; people had to rely on natural and biotic phenomena to set their time. Time was closely tied with human activities, and time in the lives of the people corresponded directly with temporal events in nature. According to Gurevich (1976, p. 231), "all modes of time, past, present and future, are so to speak situated on the same plane, in a sense 'simultaneous." "Time is either immobile or cyclical, but in either case it reflects the typical medieval system of identifying the earthly and human realm with the eternal heavenly or metaphysical realm.

Another characteristic of the medieval conception of time is that there is a radical separation between what could be called "global" or "cosmic" time from "local" or "mundane" time. The first belongs to the metaphysical realm. In Buddhist terms, global time is measured by eons or kappas, each an immensely long period of time scarcely imaginable by mere mortals (Jayatilleke, 1975, pp. 102-103). The latter, on the other hand, is measured in days, months, and years, and is thus a very tiny fraction of the global, cosmic time. However, as the local and the global are seen to mesh with one another in the medieval mind, global and local times also mesh. Global time is immanent and is present in mundane time, and the latter is a mere particular expression of the former when viewed in relation with the mundane and the ephemeral.

\section{MODERN CONCEPTION OF TIME}

The medieval conception stands in a sharp contrast with the modern conception of time, which is dominant today. Perhaps the most important characteristic of the modern mind is that it refuses to recognize the metaphysical foundation of intellectual and moral authority. Instead, such authorities are to be found within humans themselves or from their societies. In the case of time, there was a shift to the conception of time as abstract duration. The invention of mechanical clocks effectively divorced time from space, whose union was the basis of the medieval conception (Giddens, 1990, pp. 17-18). Time becomes like modern space, which is empty and is the same everywhere (Burke, 1985, p. 276). With the advent of the mechanical clock, time ceased to be exclusively connected with natural phenomena and people's lives became connected instead with its beat (Lee \& Liebenau, 2000b, p. 47). Time became quantified and commodified. As Appadurai (1996) points out, time itself becomes consumable, and leisure time is as much work as work itself (pp. 79-85). Time becomes an essential aspect of individual consciousness. Time is viewed as moving steadily from the past toward the future. This makes the present time itself razor sharp, and a useful model is this razor-sharp edge of the moment of present moving forward in a straight line to the future.

With modern time, global time in the medieval sense dropped out of the picture, being discarded together with the metaphysical source of authority. Since authority is now based on individual or collective reasons and experiences, local or mundane time becomes the only available conception. Kant thought that time itself is not an objective phenomenon, but rooted firmly in individual consciousness and understanding. It is this element of conscious ness, argued Kant, that appears to observers as objective time wherein events take place (Kant, 1929, pp. 74-82). Kant's argument is highly sophisticated; nevertheless, it suffices here to note that as a representative of the modern period, Kant brought time down from the cosmic realm of metaphysics to the mundane, ordinary level of individual consciousness.

\section{Global Time and Local Time: Time-Keeping Machine as a Hegemonic Instrument}

According to the modern conception, "global time," instead of referring to time as one with the eternal cosmos, refers to the results of scientific and technological system of time measurements, which have become more and more accurate. These instruments of time made available new ways of knowing and controlling nature as never before existed. What is noticeable is that the old medieval sense of mundane time in various cultures then became "local time." Due to the expansion of the Europeans and their ways of thinking and practicing throughout the globe in the past four or five centuries, time-keeping in most countries of the world today changed from the old system of observing nature in the locality, to the familiar one of relying on Western calendars and clocks. Time is divided 
into the familiar seconds, minutes, hours, days, months, years, and centuries, instead of according to whatever was available in the respective local cultures. The Thais, for example, used to have a totally different ways of dividing up time, but today this system is of interest only to antiquarians.

The instruments of global time were not only those of making and measuring time; they were also great instruments of power, as the "emptying of time" was a precondition for the emptying and control of space (Giddens, 1990, p. 18). The chronometer, perfected in Britain in the mid 18th century, made it possible for the first time to calculate the longitude (Sobel, 1995). This had a far-reaching implication toward the rise of Britain as a world power. As British vessels - and later those of other European nations as well-were able to learn their exact location on earth, navigation became much more accurate. As a result European vessels were able to roam all the oceans of the world without the danger of becoming lost. They inevitably came into contact with other civilizations, creating huge disruptions. Time-keeping systems in these cultures also suffered, as the indigenou s ways of taking account of time were swamped by the European system brought by the colonizers.

Map making also became much more accurate as a result of the power of global positioning through the chronometer, and became another instrument of power. As maps could be regarded as a way a culture views itself and its environment (Walsham \& Sahay, 1999), how the surroundings appear to a culture and how its dominant system of thinking is reflected (Winichakul, 1994, pp. 47-51), European maps based on longitudes and latitudes and the Mercator scale became the "universal" map. This map replaced those of other civilizations, which paid more attention to how the world was represented according to their metaphysic s than to how it was represented "as it really is" according to the modern cartographic method. The global thus forced the locals out of the big picture. Mercator maps became dominant, and together with it the modern European system of thinking based on modern science and rationality.

Moreover, as modern maps divide the regions of the world into time zones, time becomes an integral part of the modern map. The time zones are results of agreements of various nations to organize the world temporally. Since time zones are politically decided rather than based solely on geography, this has created some anomalies. China, for example, has only one time zone, based on Beijing time, across her vast area. Consequently, western regions such as Xinjiang and Tibet remain very dark while their clocks, mandated to be set to Beijing time, say 8 o' clock in the morning. Here the presence of political control of time can scarcely be ignored. Moreover, the internationally agreed time zone system allows one to calculate the time of any region on the map compared with that of another region. Thus the times of all the regions of the world are made commensurable, in effect creating a single system throughout the world.

We see now that in the modern world there is a deep distinction between the global time and the local time, as part of the distinct world systems, and that global and local times are intertwined with politics and power relations among cultures. Global time is connected with the powerful and dominant; the latter then became marginalized, existing seemingly as remnants from times past, mostly serving only symbolic and ceremonial functions. Here is a concrete aspect of how the "universal" solar-based calendar system became the dominant one in local cultures that already had their own way of measuring time.

\section{TIME, THE INTERNET, AND THE DILEMMA OF GLOBALIZATION}

The advent of information and communication technologies has created a dramatic impact on the existing conception of time. Many computers come equipped with a connection through the Internet to one of the several provided NTP (Net Time Protocol) servers, which effectively tells the client machine the time according to the time zones set by the user. Since the time zone of the machine can be set by the user, the machine in effect does not stand in the local time zone. Instead it floats about and can belong to any time zone whatsoever. Time is completely disconnected from place, or even space. The clock in these computers is not set by referring to any locality, but is set through the network to one of the NTP servers very far away. Thus when one sets one's watch after one of these wired computers, in effect one does not belong to the nation or the place where one happens to be in. One can be a citizen of the world itself.

If it is true that time and politics can thus be interconnected, then the centripetal pull exerted by the NTP servers would imply that power can be concentrated in the hands of the few who own and operate them. One's clock set according to remote time servers would be analogous to a locality following the dictate or the decree of a central authority far away. Hence it appears that the time servers can be metaphorical or symptomatic of a complete domination of localities by a global power. In short, it would seem that the Internet can become a very powerful instrument of global domination. If time can be controlled from far away through the Internet, then everything can be so controlled.

However, as Mike Sandbothe (1999) has shown, the Internet itself also opens up a possibility for the very opposite. According to Sandbothe, time as a function of communication systems stands to change when the communication system is of such a nature that allows for multilevel, multifaceted, and hypertextual communicative channels. 
The linear mode of time can be found in televisions, which allow for only one direction of communication. Hypertextual or computer-mediated means of communication, on the other hand, enable participants to blaze their own paths of linear progression. Participants are not constrained by the linear progression that the mainstream mass media offer. This situation has a profound implication as the notion of time itself is released from the modern conception of linearity and hegemony toward a more individualize $\mathrm{d}$ or personalized conception of time, which is more attuned to the mass or to the individuals themselves rather than to the decisions of the broadcasters of the mainstream media or the global setter of time alluded to earlier. With the hypertextual nature of communication, those in the mass no longer have to contend with any content pushed to them by the broadcasters; they have the power to bring their own content toward a much wider audience than hitherto imaginable. They also have the power to create a pattern of information consumption that is uniquely their own (Sunstein, 2001 ). Many commentators, such as Mark Poster (1999), have also noticed this phenomenon, and they see that this could result in a loss or an erosion of national sovereignties, as they have no effective means to control the content of the Internet. Ayres (1999), for example, sees that the Internet is making it possible for grass-roots street protests to thrive, catching established political establishments off guard. As the NTP server happens to erode the power of the state to set the time, multichannel communication is also a way citizens can bring power to themselves. In either case, the state loses its power to set the time.

This situation indicates that the modern notion of time as hegemonic and linear can be challenged and problematized. On the one hand, Internet time can be an expression of domination of the local by the global. Time ceases to be integrated with each different place, but becomes a function of the global network. On the other hand, Sandbothe (1999) points out that the Internet itself makes it possible for the locals to assert their own identitie s and to project their power vis-à-vis the global. Thus it becomes possible for there to be both a single global time and a multitude of local times. What is immensely interesting is that these times exist together, side by side as well as one on top of the other, at the same time. This creates a challenging conceptual problem of how to figure the whole thing out. More specifically, the problem is: How could one make sense of this situation where there is a single global entity covering the whole area of the world while at the same time there is a plethora of different entities of the same type each covering their own special place but taken together covering the whole world too? How is it possible for there to be one single universal time standard as well as many different time systems, one each for each of the world's cultures or communities?
In order to make sense of these questions, one has to bear in mind that time does not merely exist as one of the coordinates of the space-time continuum studied in modern physics; time is also intimate to the lived experiences, shared memories, and community structures that make up human cultures. Here the single universal time refers to the fact that the contemporary world is characterized by the prevailing trend of globalization, whose engine is driven by the Internet, among other factors. These question s raise an important issue of what I would like to call the dilemma of globalization. Many commentators, such as Robertson (1995), have noted that globalization is accompanied by localization. Robertson's term glocalization is obviously a combination of these two words, implying that the two processes always go together. However, the dilemma of globalization happens when a local culture faces the need to merge with the globalizing tide but at the same time feels that it needs to protect its identity and tradition. Since identity and tradition often run counter to globalization, and globalization requires at least some changes in tradition and identity, the dilemma can be acute. I believe that to reconcile these conflicting pulls and to resolve the dilemma is one of the most urgent tasks facing local cultures of the world nowadays.

\section{DILEMMA IN ACTION: TIME IN THAILAND}

\section{Traditional Time in Thailand}

Niels Mulder reports that there are three different conceptions of time at work in contemporary Thai society (Mulder, 1996, pp. 135-137). The first conception is characterized by continuity. It is the belief in continuity of life, traditions, and the environment, from the ancestors into endless future generations. In this sense, time stands still and is taken for granted. Past, present, and future are indistinct from one another. In short, Mulder's first conception is the same as the medieval conception of time discussed earlier.

Mulder's second conception is also the same as the modern conception of time discussed earlier. Instead of standing still and being eternal, time in this conception moves relentlessly ahead and leaves everything behind in its march toward the future. Past, present, and future are all different from one another in essential respects. Mulder also says that this notion of time came with the advent of modernity in Thai history (Mulder, 1996, p. 135). For a poor Thai, this means that time is now measured in terms of working hours in a factory when he or she has migrated into the urban area in search of better paying jobs. Instead of working in a field on an unending cycle, this person's life is measured according to a quantified amount of time translating into wages. For Mulder, this means that 
continuation of tradition s and belief systems can no longer be taken for granted. On the contrary, people lose their anchor with the past, "and their time perspective has become short and transitory with only a modicum of continuity expectations" (Mulder, 1996, p. 136).

The coming of the modern conception of time into the Thai cultural horizon has generated, according to Mulder, the third conception, namely, the animistic conception of time. Groups or communities feel that they are bounded by strong power beyond their control. Thus they seek for ways to "manage" the power through various means, which include sacrifices of various animals, worshipping and placating the deities supposed to possess the external power. There is a strong patron-client relationship between the people or villagers and the gods. The people would offer sacrifices and worship the deities, and in return the gods are expected to grant the villagers some favor, such as permitting it to rain at appropriate times, to have rich crops and so on. What is noticeable in this relationship is that the villagers would never know for sure if and when their propitiation s would work. This element of uncertainty has incurred a sense that the future, especially long-term future, is not to be trusted, and that the present time is all important in life. Mulder argues that this explains the Thais' general distrust of the long-term future and planning. Life consists of a series of relatively short events, each not necessarily connected with one another. Since the villagers cannot know for sure whether they will have a good crop this year, even though they have gone through all the proper means of satisfying the deities, Mulder sees Thai people to have generally developed a sense that the present actual gain is worth infinitely more than future prospects, no matter how much they are carefully planned (Mulder, 1996, pp. 136-137).

A remarkable aspect of contemporary Thai society is that all these notions of time still exist together. A villager from a rural area lives under the premodern conception of time. In most cases, however, he or she goes to Bangkok in search of jobs and returns home during the summer Thai New Year holiday to stay with his or her family. Thus he or she shuffles between the modern conception in Bangkok and the traditional one back home. All of his or her life, moreover, is permeated by the animistic notion of time, which successfully explains most cases of typical Thai behavior.

Nonetheless, the encroachment of the globalizing tide into the fabric of Thai society is going on at a relentless pace. It remains to be seen how long the traditional notion of time is going to hold out now that the Thai government has made it a policy to put every village in the kingdom on the Internet. Here is where the dilemma of globalization can be most visible. The awareness that local cultural identity needs to be protected only arises when it is threat- ened by a powerful external force. In Thailand, a strong movement in favor of globalization is gathering steam and is surging forward, only to be matched by the antiglobal ization movement, which is almost equally as powerful. In Mulder's case, the clash is between the traditional and animistic notions of time (both seem to be natural allies) and the modern one. However, globalization, spurred on by the Internet, problematizes even the modern conception of time. As work is no longer confined to the factory walls, the linear and monodirectional conception of time loses its bite. As the Internet seems to make it possible to work in an "asynchronous" mode, there is no need to work linearly in an assembly line, a situation well reported by Castells (1996). How this change brought about by the Internet is going to affect local cultures such as the Thai one is one of the most interesting topics of research today.

\section{A Case Study: The Debate on Advancing the Clock in Thailand}

An illustration of the dilemma Thailand is facing concerns the current proposal by the Thai government to change the country's standard time from 7 hours ahead of Greenwich Mean Time to 8 hours. On July 18, 2001, Prime Minister Thaksin Shinawatra told reporters that his government had ordered a study of the pros and cons of moving the country's clocks one hour ahead (Novel Idea to Wind Up Economy, 2001). A reason for the move was that the country's time zone would then be the same as those of Hong Kong and Singapore, making financial interactions between Thailand and these two powerhouses easier.

However, the proposal sparked a widespread debate. Those who opposed the move said that the move was unnatural, as the current time standard of GMT +7 was based on the calculation of the location of the country on the $105^{\circ}$ longitude, which makes it exactly 7 hours ahead of Greenwich Mean Time. Moreover, the $105^{\circ}$ longitude is in fact on the far eastern part of the country, making the actual, sun-based time in Bangkok actually around $20 \mathrm{~min}$ utes earlier than the national time. Thus, if the national time were moved one hour ahead, the discrepancy between actual time in Bangkok and the declared time would be as much as 80 minutes, creating a rather wide gap between nature and the clock. In order to counter this, proponents of the move contended that Singapore and Malaysia currently have the GMT +8 system, even though they lie roughly on the same longitude as Thailand. Both countries now enjoy a greater advantage than Thailand in terms of global transaction, especially with the financial markets in Hong Kong, because of their being on the same time zone as Hong Kong. Singaporeans and Malaysians, however, don't seem to mind the gap between nature and their clocks. 
We can see that this debate is centered around different ideas on how to set the clocks. Opponents of the move believe that nature at the local location should be adhered to, whereas proponents think that the clocks should be set in such a way that gives the country the most advantages. In any case, the debate shows that the impact of the global network on time is real and palpable. The reasons for the move cited by its proponents boil down to the belief that, due to the global network of information, the country would be at a disadvantage if the time were not moved ahead. But if this were true, then that would mean that the information and communication technologies are powerful enough to change the country's time standard as well as the Thai people's ways of life. Thais would have to rise earlier, for example.

This example shows a real case of the conflict between globalization and the moves to resist it. At the moment, the opponents to the move seem to have the upper hand, for most people are still attached to their nature-based time system. But that does not imply that in the future Thailand will not have to consider the move again. If Thailand does in fact suffer the losses that the proponents of the change fear, then the dilemma is all the more visible. On the one hand, there is the pull toward nature, trying to keep time tied up with natural condition s at a locality. On the other, there are demands that, to integrate more fully with globalization, the country would have even to create a disruption between its time and its nature.

\section{SOLUTION OF THE DILEMMA: LOCAL TIMES WITHIN GLOBALIZATION}

The debate on advancing the clock illustrates how tangible the impact of the Internet is on time. We have seen that the Internet can be a very powerful agent of globalization. The example of the NTP server just alluded to shows that every corner of the world, having been brought together under one familiar framework of 24-hour days, 7-day weeks, and the solar Gregorian calendar, stands to be homogenized further by perhaps a single time zone across the globe. If this actually happened, then the globalizing process would seem complete.

Nonetheless, I am quite confident that this completion of globalization would not occur, at least if concerted effort is taken now. The Internet does have the potential of bringing about such a condition; nonetheless, it also has power that can be used by local cultures to assert their identities. The world has witnessed repeated instances of conflicts between the globalizing, centripetal force and the local-oriented, centrifugal force that resists it. These instances can be seen anywhere from the present demonstration against globalization in Genoa, Italy, to the Thai villagers' and intellectuals' protests against multinational retail chains.

\section{The Internet as a Localizing Factor}

What one gains from Sandbothe's argument given earlier is the recognition that the Internet can bring back the medieval conception of time where the global and the local exist together in harmony. This return will obviously not be the same as a nostalgic yearning for the unreachable past. Instead, it is the recognition that the present time is not desirable and that there exist alternatives to it. In fact, there is now a growing number of works showing that the world permeated by information technology does not necessarily appear culturally monolithic and dominated by the West. On the contrary, as Charles Ess (1999, pp. 330-331) points out, the vision of an "electronic global village" rests on assumptions that are already culture bound. Moreover, the new communication media seem to enhance cultural differences rather than diminish them (Ess, 1999, p. 330). In philosophical terms, the belief that technology will bring about a monolithic global culture is a case of technological determinism, the view that social life is completely determined by technology. However, Ess shows a number of studies indicating that (hard) technological determinism may not be tenable (Ess \& Sudweeks, 2001, p. 17). As I have also tried to argue elsewhere, there are constant negotiation s in local cultures as to which elements are to be adopted into the local "cultural universe" and which are to be kept out as they are perceived to threaten the identities of the local cultures (Hongladarom, 2000).

When the Internet makes possible instantaneou s communication across the globe, what happens is that this mingling of the global and the local-a very identifiable outcome of globalization in a local culture-becomes more pronounced. A rather surprising aspect of this global diffusion of information technology is that there are calls for return to local cultures and traditions. Eiko Ikegami argues that the universal logic of what she calls "cyberfinancial globalization" needs to be tempered by liberal democracy (Ikegami, 1999, pp. 887-888). In the same vein, Paul Virilio claims that real time has subsumed real space and points out the need for local values and democracy to resist the tide of globalization. The emergence of global time, for Virilio, is in conflict with representative democracy, also showing the conflict between globalization and democracy as a means toward resisting it (Virilio, 1995). One difference between the new information technology and the older technologies such as telephones or gunboats is that the possibility of hypertextual communication afforded by the former is such that the local, the disenfranchised, and the underprivilege d are more able to assert their own agendas on the global scale. Under the older technology system, communication tended to be one-way. Carey notes that communication was necessary in the modernist, nation-building period of a polity since it allowed for consolidation of different parts of the policy 
and assertion of the centralized control of the bureaucracy. He calls this the "transmission" view of communication (Carey, 1989, pp. 18-23). Emphasis was placed on directives from the central toward the periphery. However, the multidirectional nature of the Internet makes the idea of centralized communication channels suspect. Though the current tendency on the Internet tends to favor large portal web sites containing a lot of information and visited by millions of visitors a day, there are also millions of smaller web sites catering to every taste and every agendum.

\section{Interplay between the Global and the Local: "Thick" and "Thin" Conceptions}

These multifarious means of communication show that the global and the local on the Internet, or as affected by the Internet, are much more difficult to distinguish than before. The global could be represented by the transnational media offering their content catered to the global audience. But I have elsewhere tried to show that, following Michael Walzer (1994, pp. 1-19), such global media can offer little more than a "thin" content since the content has to be spread out to cover the entire globe (Hongladarom, 1999, 2001). In this case the global media content offers relatively little to the real concerns of the local people. As every place in the world is a local, the global content then appeals to everywhere and to nowhere at the same time. Thus the "thin" content has to be complemented by the "thick" local content, and here we find interactions among the locals among themselves that constitute their lives and cultures. Carey calls this way of communicating the "ritual view" (Carey, 1989, pp. 18-23). The relation between the global and the local on the Internet is thus not characterized solely by the global dominating the local completely, but by the local being resilient, finding ways to preserve its identity and at the same time being merged into the global order. This is possible, I suggest, through the recognition of the "thick" and "thin" elements where the former refers to the unique identity, history, and tradition of a local culture, and the latter to what is applicable and adoptable everywhere without creating disruption in terms of cultural identity (Hongladarom, 2001).

Here is where the Internet is bringing back the lost picture of the medieval conception of time, albeit in a modified form. The potential of the Internet to merge regions of the world together through its communicative power makes it possible for the local to be immanent in the global, and vice versa. As the locals increasingly interact with one another, a situation greatly facilitated by the Internet, at first glance it might appear that the uniqueness of a locality might be dissolve dinto the ocean of the Internet. But actually the opposite has been the case. The fast-expanding web sites, chat forums, and newsgroups in languages other than English, as well as the well-documented attempts by computer corporations to "internationalize" their products and services, indicate that the locals are here to stay. They are no longer the separate locals of the medieval time, where there were less interactions and cultural exchanges. They are instead interacting and exchanging locals, altogether constituting the global scene.

Since these locals largely communicate with one another (for it is more comfortable talking in one's own vernacular with those with whom one already shares a lot of background than with strangers with whom one shares very little, and with whom one has to talk in a foreign language), what Hershock (1999, p. xii) calls "colonization of consciousness," or reconfiguration of thinking and beliefs brought about by the technologies and those who control them, does not necessarily happen. Hershock is afraid that an effect of globalization will be that locals will think the same way all over the world, and more importantly that everyone will think in the way that whoever is running the world wants them to think. The fear is clearly justified. However, Hershock seems to neglect the power of the locals to negotiate and to adopt the globalizing tide for their own use. In fact, the communicative acts the locals would be performing anyway through other, older means appear mostly the same on the Internet. When I discuss things with my Thai colleagues on the Internet, I also have to pay attention to the protocols and standards that govern normal linguistic usage. Otherwise I would appear "unThai" and complicate the communication unnecessarily (Hongladarom \& Hongladarom, 1999).

Consequently, the Internet opens an avenue where preservation of local cultures, including local times and time measurement systems, is possible. As an illustration, Thailand is slowly emerging from the brink of collapse due to the economic crisis in 1997 , and it does so not by excluding itself from the world, but by integrating with it more deeply. However, this does not mean that Thailand throws away its cultural traditions. Hence local times can and do indeed exist in the cyberworld. Indeed they are all the more necessary as live alternatives from the dominant time system. They are there for people to realize that other times do exist, and we are not bound by the time we now live in. Local times can be used to criticize the ideas presupposed by the dominant global time. Without them, such a criticism would lack much of its bite.

In Thailand, local time-time based on the traditional lunar calendar and on attunement with nature-is thriving. Religious holidays are still rigorously observed by a large proportion of the population. These holidays are counted according to not the Western solar calendar, but the traditional one. Monks perform their duties according to the same lunar calendar. The king performs his rites and ceremonies according to the same calendar, and so on. These traditional times occur in the same place and at the same time as such modern events as the openings and 
closings of financial markets, the global satellite news, and so on.

It may be argued that the local lunar calendar serves mostly symbolic functions, but symbolic functions are very important. Symbols are partly constitutive of the country's heritage and cultural identity. As people find their moorings not only in the mega-malls, but also through their roots in order to learn where they are from as a distinct people and where they are heading to, the symbols are vital. There need not be conflicts between simultaneous uses of the global time and local time, as Thais can buy their stocks under the globalized time but go to their Buddhist temples under their traditional local time. Different areas of life call for different coordinates, and they call for different times.

It remains to be seen more clearly what effect the Internet would bring to these coexisting conceptions of time. This would require further empirical research. What I have tried to show is only that if Sandbothe's argument is tenable, then there is a way to maintain local temporal identity through the use of the Internet. Thus, even though the Internet is a globalizing agent, in fact it is also a localizing agent at the same time.

\section{CONCLUSION}

If all this is indeed the case, then we can see that time, as a function of social and communication systems, is in the age of the Internet something much more fluid and dynamic than in any previous historical periods. Time in the medieval period (or in the medieval conception) is static and perfect. Perhaps it could be represented by a circle, since it symbolizes perfection and changelessness. Time in the modern period (or in the modern conception) is symbolized by an arrow pointing upward, with the arrow standing for linear time. But what should symbolize time in the information age? Perhaps it is a web or a net. Time as a function of the Internet is obviously not static and changeless as in the medieval conception, for the horizons of modern humans are no longer bound by traditional belief systems. Modern humans are no longer bound by the modernist conception of an arrow of time pointing toward a distant horizon either. The arrow does not have to point in one direction only, but there are multiple arrows pointing in multiple directions.

The advent of the Internet puts us in a difficult dilemma. Are we entering a new age, the postmodern one, or are we still living in the same modern age, only with more radical and more rapid changes? Jackson (1996) argues that the Western philosophical tradition has reached an impasse through its own critical activity, and the only way out is to return to the tradition from which the critical activity itself takes root. What this implies in our case is that the emerging society will not be too different from what we are already familiar with, only that it is much more compressed and dynamic. In any case, it is quite obvious that some profound changes are going on, characterized by time being more accurately modeled on a web or a net, where there are many times occurring together, each time represented by one strand in the web. These strands are then woven together to create a single pattern, a single picture of the global. The web of time shows that time is neither static nor constraine d by the monolithic direction of a single arrow pointing upward (or pointing anywhere, for that matter). The web is dynamic in that many movements are possible on it. One can imagine one movement along a strand in the web in one direction, and another movement along another strand in an opposite direction, and indeed there can be movements in any direction on any of the strands on the web, all occurring at the same time. This model looks like a chaos, but in fact it is not. For through the multifarious movements and interactions on the web, there emerges a single pattern of globality, of a coherent picture that should enable us to understand the whole thing together.

The look of the emerging information society can be seen in images created by myriad smaller images arranged together according to computer algorithms. A portrait of Bill Gates, for example, can be created by putting together hundreds or thousands of small clippings of Microsoftrelated images. When the picture is viewed from afar, one sees the portrait of Bill Gates; however, if one sees the picture up close, one does not see the richest man in the world, but a lot of small pictures apparently having nothing to do with one another. The picture can be an ana$\log$ to the contemporary situation in that the big picture might refer to the global situation, which spreads and covers the whole area. This big picture, nevertheless, is created out of different small pictures, representing the local cultures, which interact with one another. Each small picture is a complete picture; so is each local culture participating in the global arena. But that does not preclude the local cultures from being parts of the big picture. The local cultures, the different time strands, different conceptions of time occurring together, are then the small pictures creating a giant mosaic of contemporary world where we now live.

\section{REFERENCES}

Appadurai, Arjun. 1996. Modernity at large: Cultural dimensions of globalization. Minneapolis: University of Minnesota Press.

Ayres, Jeffrey M. 1999. From the streets to the Internet: The cyberdiffusion of contention. Annals of the American Academy of Political and Social Science 566:132-144.

Burke, James. 1985. The day the universe changed. Boston: Little, Brown.

Carey, James. 1989. Communication as culture: Essays on media and society. Boston: Unwin Hyman. 
Castells, Manuel. 1996. The rise of the network society. Blackwell.

Ess, Charles. 1999. Cultural attitudes toward technology and communication: New directions of research in computer-mediated communication. AI \& Society 13(4):329-340.

Ess, Charles, and Sudweeks, Fay, eds. 2001. Culture, technology, communication: Towards an intercultural global village. Albany: State University of New York Press.

Giddens, Anthony. 1990. The consequences of modernity. Stanford, CA: Stanford University Press.

Gurevich, A. J. 1976. Time as a problem of cultural history. In Cultures and time, eds. L. Gardet, A. J. Gurevich, A. Kagame, C. Larre, G. E. R. Lloyd, A. Neher, R. Panikkar, G. Pàttaro, and P. Ricoeur, pp. 229-245. Paris: UNESCO Press.

Hershock, Peter D. 1999. Reinventing the wheel: A Buddhist response to the information age. Albany, NY: State University of New York Press.

Hongladarom, Krisadawan, and Hongladarom, Soraj. 1999. Politeness ideology in Thai computer-mediated communication. Paper presented at the International Symposium on Linguistic Politeness, Chulalongkorn University, December.

Hongladarom, Soraj. 1999. Review of Wendy Griswold, Cultures and Societies in a Changing World. AI \& Society 13(4):446-449.

Hongladarom, Soraj. 2000. Negotiating the global and the local: How Thai culture co-opts the Internet. First Monday 5.8(August 2000) Available at http://firstmonday.org/issues/issue5_8/hongladarom/ index.html

Hongladarom, Soraj. 2001. Global culture, local cultures and the Internet: The Thai example. In Culture, technology, communication: Towards an intercultural global village, eds. Charles Ess and Fay Sudweeks, pp. 307-324. Albany: State University of New York Press.

Ikegami, Eiko. 1999. Democracy in an age of cyber-financial globalization: Time, space, and embeddedness from an Asian perspective. Social Research 66(3):887-915.

Jackson, F. L. 1996. Post-modernism and the recovery of the philosophical tradition. Animus: A Philosophical Journal of Our Time, 1. Available at http://www.mun.ca/animus/1996vol1/jackson.htm

Jayatilleke, K. N. 1975. The message of the Buddha. London: Ruskin House.
Kant, Immanuel. 1929. Critique of pure reason (Norman Kemp Smith, transl.). New York: St. Martin's Press.

Lee, Heejin. 1999. Time and information technology: Monochronicity, polychronicity and temporal symmetry. European Journal of Information Systems 8(1):16-26.

Lee, Heejin, and Liebenau, Jonathan. 2000a. Temporal effects of information systems on business processes: Focusing on the dimensions of temporality. Accounting Management and Information Technologies 10:157-185.

Lee, Heejin, and Liebenau, Jonathan. 2000b. Time and the Internet at the turn of the millennium. Time \& Society 9(1):43-56.

Mulder, Niels. 1996. Inside Thai society: Interpretations of everyday life. Amsterdam: Pepin Press.

Novel Idea to Wind Up Economy. 2001. The Bangkok Post. Retrieved July 23, 2001, from http://www.bangkokpost.com/180701/180701_ News03.html

Poster, Mark. 1999. National identities and communications technologies. The Information Society 15(4):235-240.

Robertson, Roland. 1995. Glocalization: Time-space and homogeneity-heterogeneity. In Global modernities, eds. Mike Featherstone, Scott Lash, and Roland Robertson, pp. 25-44. London: Sage.

Sandbothe, Mike. 1999. Media temporalities on the Internet: Philosophies of time and media in Derrida and Rorty. AI \& Society 13(4):421-434.

Sobel, Dava. 1995. Longitude: The true story of a lone genius who solved the greatest scientific problem of his time. New York: Penguin.

Sunstein, Cass. 2001. Republic.com. Princeton, NJ: Princeton University Press.

Virilio, Paul. 1995. Speed and information-cyberspace alarm! Canadian Journal of Political and Social Theory/Revue canadienne de theorie politique et sociale 18:82-89.

Walsham, Geoff, and Sahay, Sundeep. 1999. GIS for district-level administration in India: Problems and opportunities. MIS Quarterly 23:39-66.

Walzer, Michael. 1994. Thick and thin: Moral arguments at home and abroad. Notre Dame, IN: University of Notre Dame Press.

Winichakul, Thongchai. 1994. Siam mapped: A history of the geo-body of a nation. Chiang Mai, Thailand: Silkworms. 